Nutzen und Risiken sorgfältig abwägen

\title{
Auch Kleinkinder gegen „Zecken“ impfen?
}

- Auch Kleinkinder können sich in entsprechenden Risikogebieten mit dem FSME-Erreger infizieren; dazu müssen sie gar nicht im Unterholz herumturnen oder durch hohes Gras waten. Zecken können auch beim Spielen im elterlichen Garten ,eingefangen“ werden. Wie der Kinderarzt und FSME-Experte Prof. Ulrich Heininger vom Universitäts-Kinderspital in Basel betont, sind FSME-Infektionen im Kleinkindalter zwar selten und verlaufen in den meisten Fällen ohne schwere Komplikationen. In Einzelfällen wurden jedoch auch bei Kindern kognitive und neuropsychologische Spätfolgen wie Kopfschmerzen, Gedächtnis- oder Gleichgewichtsstörungen beschrieben, die offenbar mit einer FSME-Infektion in Verbindung standen (Eur J Pediatr 2012;171:347-52). Die Kommission für Infektionskrankheiten und Impffragen der Deutschen Akademie für Kinder- und Jugendme- dizin empfiehlt daher, bereits bei Kindern im Alter unter drei Jahren bei entsprechendem Expositionsrisiko eine FSME-Impfung in Erwägung zu ziehen. Zuvor sollte man jedoch zusammen mit den Eltern Nutzen und Risiken abwägen: In relativ vielen Fällen (nach Herstellerangaben ca. 15\%) kommt es nach der Impfung von Ein- bis Zweijährigen zu Fieber über $38^{\circ} \mathrm{C}$, und zwar vor allem nach der ersten Spritze. Bei älteren Kindern ist das Fieberrisiko dagegen deutlich geringer.

- eo

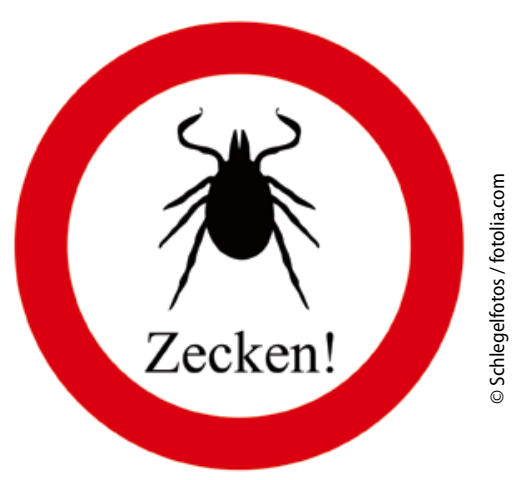

\section{Drei neue FSME-Risikogebiete}

Das Risiko, sich mit dem FSME-Erreger zu infizieren, steigt in Deutschland langsam an. Wie das RKI in seinem Epidemiologischen Bulletin zum Jahresende 2015 berichtete, sind im Vergleich zum Vorjahr drei FSME-Risikogebiete hinzugekommen: In Bayern sind dies der Stadtkreis Hof und der Landkreis Ostallgäu, in Thüringen der Landkreis Greiz (www. zecken.de). Alle drei grenzen an bereits bestehende Risikogebiete an. Insgesamt hat sich die Zahl der offiziell ausgewiesenen Risikogebiete in Deutschland damit auf 145 erhöht. Sie befinden sich überwiegend in Bayern, Baden-Württemberg, Südhessen und im südöstlichen Thüringen. In Bayern wurden bis Ende September letzten Jahres 100 FSMEFälle gemeldet, in Baden-Württemberg 54 und in Hessen 12. Laut RKI sind zwischen 0,1\% und 5\% der Zecken in Endemiegebieten mit dem FSME-Virus infiziert.

\section{Multicenterstudie}

\section{FSME-Impfung: Zusätzliche Dosis für RA-Patienten?}

Das Standard-Impfschema gegen FSME ist für Patienten mit rheumatoider Arthritis (RA), die eine immunsuppressive Therapie erhalten, oft nicht ausreichend. Das hat eine prospektive Multicenter-Studie aus Schweden ergeben.

In der Studie bekamen insgesamt 66 in einem FSME-Endemiegebiet lebende, bislang ungeimpfte RA-Patienten eine FSME-Grundimmunisierung gemäß dem Standardschema. Zur Behandlung ihrer RA erhielten 36 Teilnehmer eine Kombination aus TNF-Blocker (Etanercept, Infliximab oder Adalimumab) und Methotrexat (MTX). 16 weitere Patienten wurden lediglich mit einem TNF-Inhibitor therapiert und 14 weitere bekamen nur MTX. Einen Monat nach Verabreichung der letzten Impfdosis, also 13 Monate nach Studienbeginn, wurde der FSME-Antikörpertiter der immunsupprimierten Patienten mit dem von parallel geimpften gesunden Kontrollen verglichen. Ergebnis: Seroprotektive Titer fand man bei $79 \%$ der gesunden Teilnehmer, aber nur bei insgesamt 39\% der RA-Patienten. Dabei unterschied sich allerdings nur die Gruppe mit der Kombinationstherapie signifikant von den Kontrollen (36\% gegenüber $87 \%$ ).

Patienten im Alter von 60 Jahren und darüber hatten standardgemäß eine zusätzliche Primer-Dosis des FSME-Impfstoffs erhalten. Auch danach lag der Anteil mit seroprotektiven Titern im Vergleich zu altersgleichen Kontrollen nur bei $31 \%$ gegenüber $81 \%$.

Von den Nicht-Respondern nahmen zehn das Angebot einer zusätzlichen Booster-Dosis an. Einen Monat danach erreichten jedoch nur vier davon sero- protektive Antikörpertiter. Alle aus dieser Gruppe waren deutlich über 60 Jahre alt, hatten also vor der Boosterung bereits vier Impfdosen erhalten.

Die Forscher um Katarina Brodin Hertzell vom schwedischen KarolinskaInstitut empfehlen nun, immunsupprimierten FSME-Impflingen in jedem Fall eine zusätzliche Impfdosis über das Standardschema hinaus anzubieten, und zwar unabhängig vom Alter. Auch dann müsse man entsprechend behandelte RA-Patienten jedoch sorgfältig über den möglicherweise unzureichenden Impfschutz und die Gefahr einer Infektion mit FSME bei Aufenthalt in Risikogebieten aufklären.

- eo

- Brodin Hertzell Ket al. Tick-borne encephalitis (TBE) vaccine to medically immunosuppressed patients with rheumatoid arthritis: A prospective, open-label, multi-centre study. Vaccine 2016;34:650-655 